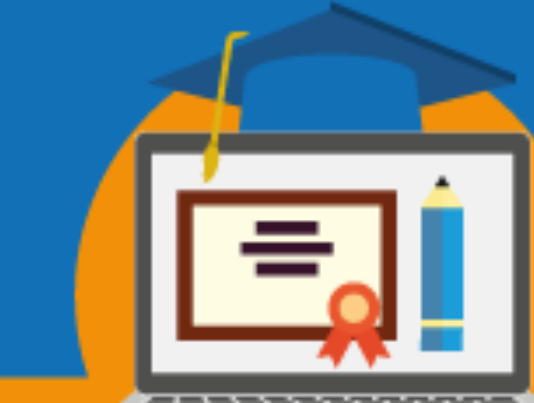

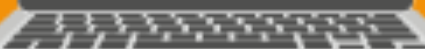

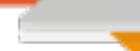

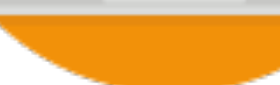

\title{
A EDUCAÇÃO A DISTÂNCIA NOS PLANOS DE DESENVOLVIMENTO INSTITUCIONẢL/PLANO PEDAGÓGICO INSTITUCIONAL DA UNIVERSIDADE FEDERAL DE MATO GROSSO
}

\author{
Rosemery C. Petter \\ UFMT - Instituto de Educação \\ rosypetter@gmail.com \\ Cristiano Maciel \\ UFMT - Instituto de Computação \\ crismac@gmail.com
}

Eixo 01: Política, gestão e financiamento da educação a distância

\begin{abstract}
Resumo: Este trabalho tem o objetivo de identificar como a Educação a Distância é apresentada no Plano de Desenvolvimento Institucional e no Plano Pedagógico Institucional da Universidade Federal de Mato Grosso, indicando as políticas e estratégias traçadas para essa modalidade educativa nos referidos documentos institucionais. Foram analisados os documentos relativos aos períodos 2005-2010, 2013-2018 e 2019-2023. Como resultado da análise realizada, constatou-se que a Educação a Distância obteve importância crescente nas políticas, nos objetivos, nas metas e nas estratégias institucionais. Contudo ainda não existe uma política institucional de Educação a Distância, de modo a identificar a identidade institucional própria dessa modalidade educativa.
\end{abstract}

Palavras-chave: Educação a Distância. Plano de Desenvolvimento Institucional. Plano Pedagógico Institucional.

\section{Introdução}

A Educação a Distância (EaD) é uma modalidade educativa que vem se destacando no contexto brasileiro, sobretudo nas últimas décadas, como uma das formas de democratização do ensino, levando a educação superior às regiões distantes do país e às pessoas que não teriam a possibilidade para realizar um curso presencial.

A EaD veio a se destacar no cenário brasileiro quando da promulgação da Lei de Diretrizes e Bases da Educação Nacional (LDBEN) n 9.394/96, em que essa modalidade deixa de ter caráter emergencial e supletivo. Seu reconhecimento vem a ser definido em um conjunto de documentos legais que determinam os critérios e as normas para a criação de programas e

\section{SEMINÁRIO DE EDUCAÇÃO A DISTÂNCIA}

Diálogos sobre EaD e uso das TDIC na educação: regulamentação em tempos recentes 3 a 6 de novembro de 2020 - Brasília/DF - Online 
cursos nessa modalidade, distintos do ensino presencial. Além de um ordenamento normativo, foram empreendidas políticas públicas para a modalidade, fundamentais para a sua inserção nas Instituições de Ensino Superior (IES), em especial as públicas.

Devido às políticas educacionais fomentadas pelo governo federal nas últimas décadas, sobretudo da criação e viabilização do Programa Universidade Aberta do Brasil (UAB) em 2006, ocorre o aumento de vagas em cursos de graduação e a implementação de cursos de pósgraduação lato sensu e aperfeiçoamento na modalidade a distância nas Instituições Públicas de Ensino Superior (IPES).

A Universidade Federal de Mato Grosso (UFMT) possui uma história de pioneirismo na inserção institucional da modalidade a distância, pois em 1994 cria o primeiro curso de licenciatura em Pedagogia nesta modalidade no país, idealizado e implementado pela equipe do Núcleo de Educação Aberta e a Distância (NEAD) do Instituto de Educação (IE) entre os anos de 1992 a 2005 (PRETI; ALONSO, 2016). O curso foi desenvolvido inicialmente como uma das ações do Programa de Formação de Educador das Séries Iniciais. Para desenvolvê-lo, foi selado um Convênio Tripartite, firmado em 21/12/1992, tendo como parceiros a UFMT, a Universidade do Estado de Mato Grosso (UNEMAT) e a Secretaria de Estado de Educação de Mato Grosso (SEDUC) (PRETI, 2009), e de 1998 a 2002 o Programa Interinstitucional de Qualificação Docente (PIQD), que uniu em parceria SEDUC, UFMT e UNEMAT (ALONSO, 2005).

Em 2006, a instituição adere ao Programa UAB, vindo a participar de todos os editais da Capes na oferta de cursos de graduação, especialização, extensão e aperfeiçoamento. Para tanto, promove um ajuste nos documentos institucionais e na estrutura organizacional para que os cursos nessa modalidade fossem viabilizados, não somente no NEAD/IE, mas também em outras unidades acadêmicas da instituição.

Para retirar da EaD o caráter supletivo e trazê-la para o plano da institucionalização, ou seja, reconhecê-la como uma prática educativa integrada à instituição respeitando suas singularidades didáticas e organizativas (PRETI, 2009), é necessário que ela faça parte da política institucional e do projeto pedagógico da instituição. Nesse vértice, aponta Ferreira e 


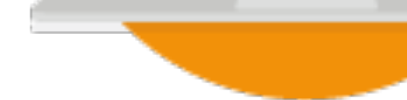

Mill (2014) que a EaD necessita fazer parte da política institucional das IES, isso porque é essencial que nelas haja a decisão política em favor da $\mathrm{EaD}$ e, em consequência, sejam viabilizadas ações institucionalizadoras.

A relevância de essa modalidade estar presente nos documentos regulatórios das IES já era apontada pelo Decreto $n^{\circ} 5.622 / 2005$, dentre estes o Plano de Desenvolvimento Institucional (PDI). Em conformidade com as Diretrizes do MEC (BRASIL, 2004), o PDI consiste em um documento que apresenta a identidade das IES e tem vigência por cinco anos. Ele deve conter o planejamento estratégico, a missão, as diretrizes pedagógicas, os objetivos, as metas, as ações e os investimentos primordiais para seu aperfeiçoamento contínuo e garantia de sua qualidade (BRASIL, 2004).

Quanto a sua elaboração, Azevedo e Azevedo (2009, p. 6) apontam que o documento “deve apresentar publicamente os princípios norteadores do funcionamento da instituição. Toda sua dinâmica e o conjunto de ações para o alcance das metas devem estar explicitados (...)" e, ainda, acrescentam que é importante que haja "adequação entre todos os seus elementos, demonstrando a viabilidade do seu cumprimento". Ademais, sua elaboração deve atender as indicações emanadas de alguns dispositivos legais, como a Lei 10.861 de 14/04/2004 do Sistema Nacional de Avaliação da Educação Superior (SINAES) e atualmente o Decreto $n^{\circ}$ 9.235 de 15/12/2017 que dispõe sobre o exercício das funções de regulação, supervisão e avaliação das Instituições de Educação Superior e dos cursos superiores de graduação e de pósgraduação no sistema federal de ensino (BRASIL, 2017b).

Em face de tais considerações e da importância desse documento, em que estão definidas as políticas que norteiam as dimensões institucionais de modo a viabilizar o tripé ensino, pesquisa e extensão, bem como responder às demandas e necessidades sociais internas e externas à instituição, pretende-se neste trabalho identificar como a UFMT apresenta a Educação a Distância no Plano de Desenvolvimento Institucional (PDI) e no Plano Pedagógico Institucional (PPI), bem como apontar quais as políticas e estratégias traçadas para essa modalidade educativa nos referidos documentos institucionais. Para tanto, foram analisados os PDI/PPI dos períodos 2005-2010, 2013-2018 e 2019-2023. 


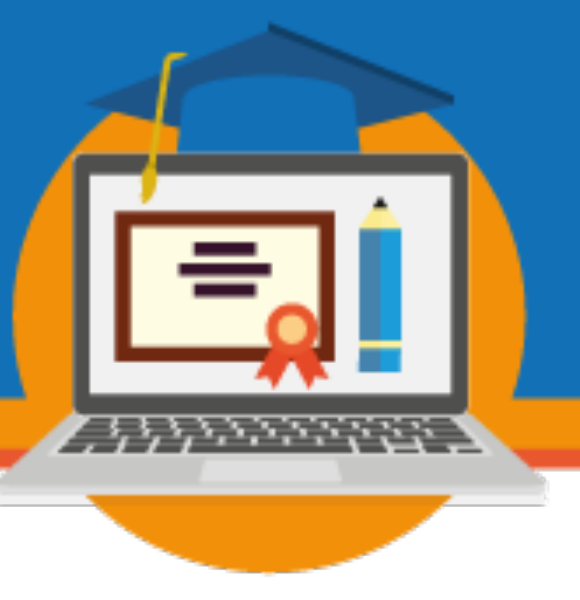

Para atender a esse objetivo, foi realizada uma análise documental que possibilita a busca por um leque de informações, fatos e episódios convergentes aos propósitos da investigação (LÜDKE; ANDRE, 1986). Além disso, Flick (2009, p. 237) acrescenta que "os documentos podem ser instrutivos para a compreensão das realidades sociais em contextos institucionais". Ao escolher a análise documental como a técnica de coleta de dados, teve-se a pretensão de buscar nos documentos institucionais elementos necessários para atender ao propósito do presente artigo. O resultado desse trabalho é o que se verá a seguir.

\section{A Educação a Distância nos PDI/PPI da UFMT: diretrizes e estratégias}

Nesta parte do presente trabalho, serão apresentados e analisados o Plano de Desenvolvimento Institucional (PDI) e o Plano Pedagógico Institucional (PPI) da UFMT, com o intuito de indicar as políticas e práticas voltadas para a EaD.

Os documentos consultados são os três PDIs da instituição, referentes aos períodos de 2005-2012 , 2013-2018 e 2019-2023. Antes de iniciar o exame desses documentos, cabe observar dois pormenores. O primeiro é que, desde o primeiro PDI da instituição, o PPI não consiste em um documento à parte ao PDI, e sim encontra-se integrado ao mesmo. O segundo é que, no PDI 2019-2023, o PPI é nominado de Projeto Político Pedagógico da Instituição (PPPI), porém essa nomenclatura será usada apenas nas partes do texto concernentes a este documento.

Com a Resolução CONSUNI $n^{\circ}$ 17, de 25 de novembro de 2005, foi aprovado o PDI de 2005-2010. Nesse documento, observou-se que, em função dos princípios condutores da instituição, são apresentadas sete prioridades estratégicas, ou objetivos institucionais, e cada uma delas foi subdividida e explicada em objetivos, metas e estratégias institucionais. Destas, consta uma menção à Educação a Distância no PDI/ PPI da instituição. No objetivo institucional

${ }^{1}$ Em 2007, motivado pelo Decreto no 6.096 de 24/6/2007, que institui o Programa de Apoio a Planos de Reestruturação e Expansão das Universidades Federais - REUNI, este PDI foi complementado com um aditivo, contendo o Plano de Reestruturação da UFMT. Para mais informações, consultar o item IX do PDI, cujo título é Aditivo do PDI - Propostas para Execução 2008 a 2012.

\section{SEMINÁRIO DE EDUCAÇÃO A DISTÂNCIA}


1, no que tange à EaD, indica "ampliar a oferta de ensino de graduação e de pós-graduação", que, em termos práticos, sinaliza duplicar o número de vagas nesta modalidade. Para implementar esse objetivo, foram indicadas cinco estratégias, sendo três delas relacionadas direta e indiretamente à EaD: ampliação da oferta dos programas para formação do professor em exercício; ampliação dos programas de educação a distância; fortalecimento do programa de interiorização da graduação (UNIVERSIDADE FEDERAL DE MATO GROSSO, 2007).

No PPI, na parte referente à "Política de Ensino de Graduação", constam as principais ações que seriam viabilizadas pela Pró-Reitoria de Graduação (PROEG): democratização do acesso; informatização do registro acadêmico; implementação da avaliação institucional; revisão das normas acadêmicas.

Dessas políticas, a que concerne diretamente à $\mathrm{EaD}$ é a democratização do acesso. Consoante a esse documento, a instituição estava executando uma "[...] política de incentivo aos programas de interiorização da graduação, de formação de professores em exercício na modalidade presencial e a distância, e a oferta de cursos no período noturno" (UNIVERSIDADE FEDERAL DE MATO GROSSO, 2007, p. 66). Em conformidade com essa estratégia, como já mencionado em outra parte deste trabalho, desde o início dos anos 1990, a instituição, por meio do IE/NEAD, vinha ofertando o curso de "Pedagogia na Modalidade Licenciatura para os Anos Iniciais do Ensino Fundamental", no âmbito de programas interinstitucionais.

Ao observar o quadro demonstrativo do número de alunos de graduação e pós-graduação por unidade acadêmica exposto no PPI, os dados chamam atenção, pois revelam a dimensão do trabalho realizado pelo NEAD. Nele consta o número de alunos matriculados (dados de 2005) nos cursos de graduação ofertados (aqui importa destacar os do IE): Pedagogia da sede, Parceladas e NEAD. Enquanto este último contava com 1.631 alunos, o curso de Pedagogia presencial da sede tinha menos de um quinto (306) desse total. Esse dado é interessante, pois revela a abrangência e envergadura da ação do NEAD, que não se restringiu ao curso de graduação e estendeu sua ação na oferta de cursos de especialização, aperfeiçoamento e extensão no período de 1995 a 2005. Outra ação que vale ser destacada é que a EaD é inserida 


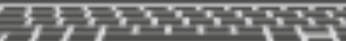

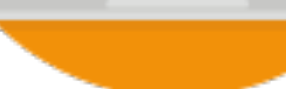

na avaliação institucional a partir de 2010, com a participação dos discentes dos cursos dessa modalidade na instituição (PETTER, 2019).

O PDI/PPI de 2013-2018, aprovado pela Resolução CONSUNI nº 12 de 3 de abril de 2013, tem como eixo de sustentação o princípio constitucional da autonomia universitária e seus princípios norteadores foram ampliados e apresentam um delineamento diferenciado daqueles apresentados no PDI/PPI de 2005-2012. Tal aspecto deve-se ao contexto socioeconômico e político nacional e regional, às políticas públicas para o ensino superior oriundas do MEC e ao surgimento de outras demandas internas e externas à instituição, relativas ao período de elaboração desse documento.

No PDI, em seu Título III intitulado "Planejamento institucional”, encontra-se o Projeto Pedagógico Institucional. Nele estão as Políticas Estruturantes 1, 2 e 3, com seus objetivos, metas e ações referentes à EaD. Nas Tabelas 1 e 2 abaixo, foram salientados os objetivos, as metas e ações que, direta ou indiretamente, tratam dessa modalidade educativa.

\section{Tabela 1 - Política Estruturante 1}

\begin{tabular}{|c|c|c|}
\hline & $\begin{array}{l}\text { tica estruturante } 1 \text { - Busca d } \\
\text { uisa e extensão, articulada c }\end{array}$ & $\begin{array}{l}\text { e maior qualidade e de indissociabilidade entre ensino, } \\
\text { om as necessidades regionais }\end{array}$ \\
\hline & jetivo 1 - Criar novos cursos e & melhorar a qualidade no ensino de graduação. \\
\hline & Metas & \\
\hline $\mathrm{N}$ & Descrição & Ações \\
\hline 1 & $\begin{array}{l}\text { Atualizar todos os Projetos } \\
\text { Pedagógicos de Curso (PPC) } \\
\text { da graduação. }\end{array}$ & $\begin{array}{l}\text { - Reorganização do Projeto Pedagógico dos Cursos, } \\
\text { adequando-os às novas concepções sociopolíticas e } \\
\text { teórico-metodológicas, às novas tecnologias e às novas } \\
\text { concepções de inclusão social; } \\
\text { - Estímulo à oferta, em até } 20 \% \text {, de disciplinas na } \\
\text { modalidade a distância para os cursos presenciais } \\
\text { (Portaria no } 4.059 \text { de } 10 / 12 / 2004) \text {; } \\
\text { - Estímulo à incorporação de tecnologias de informação à } \\
\text { educação. }\end{array}$ \\
\hline 3 & $\begin{array}{l}\text { Ampliar a oferta de vagas e } \\
\text { ocupar as vagas ociosas. }\end{array}$ & $\begin{array}{l}\text { - Oferta de novas vagas e de cursos na modalidade a } \\
\text { distância. }\end{array}$ \\
\hline
\end{tabular}




\begin{tabular}{|l|lr|l|}
\hline 4 & $\begin{array}{l}\text { Reduzir a evasão e } \\
\text { repetência nos cursos de } \\
\text { graduação. }\end{array}$ & $\begin{array}{l}\text { - Fortalecimento dos polos de apoio presencial do Ensino } \\
\text { a Distância, com ampliação das visitas pedagógicas e } \\
\text { maior número de aulas. }\end{array}$ \\
\hline 7 & $\begin{array}{l}\text { Promover a formação do } \\
\text { corpo docente }\end{array}$ & $\begin{array}{l}\text { - Capacitação do corpo docente para utilização das } \\
\text { tecnologias da informação e comunicação. }\end{array}$ \\
$\begin{array}{l}\text { administrativo, objetivando a } \\
\text { melhoria do ensino de } \\
\text { graduação. }\end{array}$ &
\end{tabular}

Objetivo 3 - Ampliar, consolidar e elevar os conceitos da pós-graduação na UFMT.

\begin{tabular}{|c|c|c|}
\hline \multicolumn{2}{|r|}{ Metas } & \multirow[b]{2}{*}{ Ações } \\
\hline $\begin{array}{l}\mathrm{N} \\
\mathrm{o}\end{array}$ & Descrição & \\
\hline 3 & $\begin{array}{l}\text { Implantar novos cursos de } \\
\text { pós-graduação stricto sensu } \\
\text { na UFMT, fortalecendo a } \\
\text { estrutura existente. }\end{array}$ & $\begin{array}{l}\text { - Implantação de novos cursos de doutorado, mestrados } \\
\text { acadêmicos, multidisciplinares e/ou profissionais, } \\
\text { presenciais e/ou a distância nos diversos campi da UFMT. }\end{array}$ \\
\hline 4 & $\begin{array}{l}\text { Implantar novos cursos de } \\
\text { pós-graduação lato sensu e } \\
\text { estabelecer rotinas de oferta. }\end{array}$ & $\begin{array}{l}\text { - Ampliação e consolidação da oferta de cursos lato sensu } \\
\text { (especializações) nas modalidades presencial e a } \\
\text { distância. }\end{array}$ \\
\hline
\end{tabular}

Objetivo 5 - Promover a Educação a Distância das Tecnologias de Informação e

Comunicação Aplicada à Educação (TIC) para a inovação das práticas pedagógicas.

\begin{tabular}{|c|c|c|}
\hline \multicolumn{2}{|r|}{ Metas } & \multirow[b]{2}{*}{ Ações } \\
\hline $\begin{array}{l}\mathrm{N} \\
\mathrm{o}\end{array}$ & Descrição & \\
\hline 1 & $\begin{array}{lcr}\text { Ampliar } & \text { e } & \text { fortalecer a } \\
\text { educação a distância como } \\
\text { forma de democratização do } \\
\text { acesso } & \text { à } & \text { universidade } \\
\text { pública. } & & \end{array}$ & $\begin{array}{l}\text { - Viabilização do financiamento da educação superior na } \\
\text { modalidade a distância; } \\
\text { - Promoção da normalização acadêmica com vistas às } \\
\text { especificidades da modalidade de oferta da educação a } \\
\text { distância; } \\
\text { - Desenvolvimento de um programa de formação } \\
\text { continuada para os docentes que permita o } \\
\text { compartilhamento de melhores práticas, utilizando-se de } \\
\text { tecnologias e metodologias de inovação didático- } \\
\text { pedagógica; } \\
\text { - Estabelecimento de uma política de desenvolvimento de } \\
\text { pesquisas sobre educação aberta, flexível e a distância no } \\
\text { âmbito de instituições públicas, buscando financiamento } \\
\text { pelas agências dos Ministérios da Educação e da Ciência } \\
\text { e Tecnologia, entre outros órgãos de fomento. }\end{array}$ \\
\hline 2 & $\begin{array}{l}\text { Ampliar o número de alunos } \\
\text { matriculados em cursos na } \\
\text { modalidade a distância. }\end{array}$ & $\begin{array}{l}\text { - Expansão das matrículas em cursos na modalidade a } \\
\text { distância nas áreas já ofertadas; }\end{array}$ \\
\hline
\end{tabular}




\begin{tabular}{|l|l|l|}
\hline \multicolumn{1}{|c|}{} & $\begin{array}{l}\text { - Fomento para a criação de novos cursos de graduação na } \\
\text { modalidade a distância; }\end{array}$ \\
& $\begin{array}{l}\text { - Fomento para a criação de curso de pós-graduação } \\
\text { stricto sensu na modalidade a distância; } \\
\text { - Ampliação e consolidação da oferta de cursos lato sensu, } \\
\text { (especializações) nas modalidades presencial e a } \\
\text { distância. }\end{array}$ \\
\hline 3 & $\begin{array}{l}\text { Ampliar as TIC aplicadas à } \\
\text { Educação para a inovação das } \\
\text { práticas pedagógicas. }\end{array}$ & $\begin{array}{l}\text { - Estímulo à utilização das metodologias inovadoras e } \\
\text { mediadas pelas TICs; } \\
\text { - Estímulo à criação e utilização de objetos de } \\
\text { aprendizagem (AO); } \\
\text { - Capacitação profissional para utilização de AVA. }\end{array}$ \\
\hline
\end{tabular}

Fonte: Petter (2019)

Como mostra a Tabela 1, no que se refere à Política Estruturante 1 "Busca de maior qualidade e de indissociabilidade entre ensino, pesquisa e extensão, articulada com as necessidades regionais", são três os objetivos direcionados a metas e ações para a EaD, especialmente o objetivo 5. Destes objetivos, a ênfase está em três aspectos principais da Política Estruturante 1: inserção dos $20 \%$ EaD nos PPC, a criação e viabilização de cursos de graduação, pós-graduação stricto e lato sensu presencial e EaD e, como uma estratégia de redução da evasão dos alunos $\mathrm{EaD}$, o fortalecimento dos polos de apoio presencial. Como o objetivo 5 é o que trata especificamente da modalidade, dele destacam-se as seguintes metas: ampliá-la e fortalecê-la na instituição, promover o aumento do número de estudantes na EaD e fomentar o uso das Tecnologias da Informação e Comunicação (TIC) nas práticas pedagógicas dos docentes, por serem elementos que favorecem o uso de metodologias por elas mediadas.

Quanto a este segundo aspecto, vale destacar o Projeto de Educação Mediada por Tecnologias da Informação e da Comunicação (PEMTIC), desenvolvido em meados de 2012 e ao longo de 2013, tendo por objetivo capacitar os docentes da instituição de modo a habilitálos para o uso de Ambientes Virtuais de Aprendizagem (AVA), na oferta parcial de disciplinas em modalidade não presencial e apoio na melhoria das estratégias de ensino-aprendizagem (ANJOS et al., 2014). O PEMTIC foi promovido pela Coordenação de Educação Mediada por Tecnologia da Informação e Comunicação (CEMTIC) da Secretaria de Tecnologia da 
Informação e da Comunicação Aplicada à Educação (STI), que veio atender o Objetivo 5, Meta 3 da Política Estruturante 1. Essa ação também poderia favorecer para que os projetos pedagógicos dos cursos de graduação pudessem ser adequados aos $20 \% \mathrm{EaD}$, preconizados na então Portaria $\mathrm{n}^{\circ} 4.059$ de 10/12/2004². Como resultado desse trabalho, desde 2014, foi disponibilizado a plataforma Moodle pela STI (atualmente sob a responsabilidade da Secretaria de Tecnologia Educacional) para uso do AVA por parte dos docentes de cursos de graduação e pós-graduação.

\section{Tabela 2 - Política Estruturante 2}

\begin{tabular}{|c|c|c|}
\hline \multicolumn{3}{|c|}{$\begin{array}{l}\text { Ampliação das relações com a sociedade, visando contribuir com o desenvolvimento } \\
\text { regional sustentável } \\
\text { Objetivo } 1 \text { - Contribuir para a melhoria da qualidade do ensino fundamental e médio no estado } \\
\text { de Mato Grosso. }\end{array}$} \\
\hline \multicolumn{2}{|r|}{ Metas } & \multirow[b]{2}{*}{ Ações } \\
\hline $\mathrm{N}$ & Descrição & \\
\hline 2 & $\begin{array}{l}\text { Ampliar e fortalecer o papel da UFMT na } \\
\text { formação e capacitação de recursos } \\
\text { humanos para atuarem na educação } \\
\text { básica. }\end{array}$ & $\begin{array}{l}\text { - Ampliação e continuidade das parcerias para } \\
\text { formação de licenciados e formação } \\
\text { continuada de professores nas modalidades } \\
\text { presencial e a distância; } \\
\text { - Participação nos Conselhos Municipal e } \\
\text { Estadual de Educação. }\end{array}$ \\
\hline \multicolumn{3}{|c|}{$\begin{array}{l}\text { Objetivo } 2 \text { - Contribuir para o desenvolvimento industrial, científico e tecnológico do } \\
\text { estado. }\end{array}$} \\
\hline & Metas & \multirow[b]{2}{*}{ Ações } \\
\hline $\mathrm{N}$ & Descrição & \\
\hline 1 & $\begin{array}{l}\text { Ampliar a atuação da UFMT nas } \\
\text { iniciativas de } \\
\text { sustentável do Estado mediante formação } \\
\text { e capacitação de recursos humanos e da } \\
\text { criação de mecanismos de apoio ao } \\
\text { empreendedorismo e à prestação de } \\
\text { serviços para a comunidade. }\end{array}$ & $\begin{array}{l}\text { - Realização, nas modalidades presencial e a } \\
\text { distância, de cursos de especialização, } \\
\text { capacitação, assim como promoção de } \\
\text { seminários, oficinas e outras atividades em } \\
\text { áreas diversas direcionadas ao apoio } \\
\text { empresarial, empreendedorismo, economia } \\
\text { solidária, cooperativismo e outros. }\end{array}$ \\
\hline
\end{tabular}

2 Essa normativa foi revogada pela Portaria $n=1.134$ de 10/10/2016 e esta, revogada pela Portaria $\mathrm{n}$ 0 1.428 $28 / 12 / 2018$. 


\begin{tabular}{|c|c|c|}
\hline \multicolumn{3}{|c|}{ Objetivo 4 - Contribuir para a melhoria da saúde pública no estado de Mato Grosso. } \\
\hline \multicolumn{2}{|r|}{ Metas } & \multirow[b]{2}{*}{ Ações } \\
\hline $\begin{array}{l}\mathrm{N} \\
\mathrm{o}\end{array}$ & Descrição & \\
\hline 1 & $\begin{array}{l}\text { Desenvolver atividades de ensino para } \\
\text { qualificação de recursos humanos na área } \\
\text { da saúde, inclusive na modalidade a } \\
\text { distância. }\end{array}$ & $\begin{array}{l}\text { - Busca de parceria com a fundação de apoio } \\
\text { para o desenvolvimento de programas e } \\
\text { projetos específicos de qualificação de } \\
\text { recursos humanos em saúde, priorizando a } \\
\text { educação a distância. }\end{array}$ \\
\hline \multicolumn{3}{|c|}{ Objetivo 7 - Ampliar a presença da UFMT nos municípios do estado de Mato Grosso. } \\
\hline \multicolumn{2}{|r|}{ Metas } & \multirow[b]{2}{*}{ Ações } \\
\hline $\begin{array}{l}\mathrm{N} \\
\mathrm{o}\end{array}$ & Descrição & \\
\hline 1 & $\begin{array}{l}\text { Interiorizar as atividades acadêmicas de } \\
\text { ensino, pesquisa e extensão. }\end{array}$ & $\begin{array}{l}\text { - Execução de projetos de educação } \\
\text { continuada, presenciais e a distância para os } \\
\text { profissionais residentes no interior de Mato } \\
\text { Grosso; } \\
\text { - Oferta de cursos de tutoria tecnológica a } \\
\text { distância para pequenos produtores rurais; } \\
\text { - Ampliação dos cursos de graduação, pós- } \\
\text { graduação, extensão e capacitação na } \\
\text { modalidade EAD; } \\
\text { - Fomento de novos polos no estado para o } \\
\text { desenvolvimento de atividades EAD; } \\
\text { - Articulação com o órgão mantenedor do } \\
\text { polo de apoio para adequação da } \\
\text { infraestrutura às especificidades do curso. }\end{array}$ \\
\hline
\end{tabular}

Fonte: Petter (2019)

Na Tabela 2, relativa à Política Estruturante 2, acentua-se o papel da UFMT como instituição pública de ensino superior na função de colaborar com o desenvolvimento regional. Nesse documento, mais uma vez, é destacada a importância do fortalecimento das parcerias com órgãos gestores da educação pública como forma de implementar a formação docente para a Educação Básica, com a oferta de cursos presenciais e de EaD.

Esse posicionamento ratifica o papel de formar recursos humanos por meio de cursos de especialização e aperfeiçoamento presencial e a distância, em outras áreas estratégicas para 
o Estado, o que indica promover maior aproximação e articulação da UFMT com os mantenedores dos polos de apoio presencial.

Cabe aqui mencionar a Política Estruturante 3 "Modernizar os sistemas de gestão e avaliação objetivando melhores resultados administrativos e acadêmicos", isso porque, no período de vigência desse documento, houve a consolidação das ações da STI, órgão suplementar voltado para a infraestrutura de Tecnologia da Informação (TI), criação e aquisição de sistemas administrativos e acadêmicos, bem como de sistemas voltados para a educação mediada por TIC. Tal aspecto revela que esse órgão teve papel importante e estratégico como suporte ao desenvolvimento da modalidade a distância na instituição, em que foram iniciados projetos e ações que envolvem a tecnologia educacional e que estão sendo continuadas e aperfeiçoadas pela Secretaria de Tecnologia Educacional (SETEC), criada em 2016 (PETTER, 2019).

No PDI/PPPI 2019-2023, aprovado pela Resolução CONSUNI n 14 de 28 de junho de 2019, a EaD encontra-se expressa nos objetivos e nas metas do Eixo de Ensino, do Eixo de Pesquisa e Inovação, do Eixo de Extensão e do Eixo de Gestão. Diferentemente do PDI/PPI anterior, neste não foram evidenciadas as estratégias relativas aos objetivos e às metas, em seu lugar foram apresentados a quantificação e os indicadores (descrição/método de cálculo e órgão responsável) e os recursos necessários ao alcance das mesmas. Nas tabelas que seguem, serão apresentados os objetivos e as metas voltados para a EaD, indicados nesse documento, conforme os quatro eixos:

\section{Tabela 3 - Eixo Ensino}

\section{Objetivos e metas do Eixo de Ensino}

Objetivo 1 - Melhorar a qualidade do ensino de graduação.

Meta 9 - Elevar o número dos cursos de graduação com sistema de autoavaliação regulamentado internamente.

Objetivo 2 - Ampliar a oferta de egressos no mundo do trabalho.

Meta 2 - Elevar o número de egressos dentro do período mínimo de integralização.

Objetivo 3 - Cooperar para a melhoria da qualidade do ensino fundamental e médio no Estado.

Meta 2 - Elevar parcerias com as redes públicas de educação para oferta de cursos de graduação por meio da modalidade a distância. 


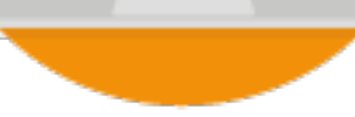

Fonte: PDI/PPPI 2019-2023 (2019, p. 28 a 30)

Tabela 4 - Eixo de Pesquisa e Inovação

Objetivos e metas do Eixo de Pesquisa e Inovação

Objetivo 1 - Estimular a pesquisa e a inovação relacionadas ao bem-estar de toda a sociedade brasileira e às necessidades regionais.

Meta 2 - Ampliar o número de grupos de pesquisa.

Meta 3 - Ampliar o número de projetos de pesquisa.

Fonte: PDI/PPPI 2019-2023 (2019, p. 33)

\section{Tabela 5 - Eixo Extensão}

\begin{tabular}{|l|}
\hline Objetivos e metas do Eixo Extensão \\
\hline Objetivo 1 - Estabelecer a extensão universitária como processo acadêmico, cultural e \\
científico articulado com a sociedade. \\
Meta 3 - Elevar a integração através de números de projetos de extensão intra e extra campus. \\
\hline
\end{tabular}

Fonte: PDI/PPPI 2019-2023 (2019, p. 35)

\section{Tabela 6 Eixo Gestão}

\begin{tabular}{|l|}
\hline Objetivos e metas do Eixo Gestão \\
\hline Objetivo 1 - Fomentar a expansão do relacionamento da UFMT com parceiros externos. \\
Meta 2 - Elevar o número de convênios, contratos e congêneres. \\
\hline
\end{tabular}
Fonte: PDI/PPPI 2019-2023 (2019, p. 37)

Ao verificar as Tabelas 3 a 6, percebeu-se que nos objetivos e nas metas a modalidade não foi diretamente mencionada, mas tais elementos são concernentes tanto aos cursos presenciais como a distância. Porém alguns aspectos referentes a EaD são apresentados separadamente em três itens, que mais à frente serão apontados. Cabe destacar que os objetivos e as metas mencionados nas Tabelas 3 a 6 têm como um dos órgãos responsáveis para sua viabilização a SETEC, que consiste em órgão suplementar, cuja função reside em "oferecer estrutura física, técnica e pedagógica para a execução de cursos na modalidade a distância, levando em consideração as especificidades de planejamento dos cursos, execução, controle, regulação e avaliação" (UNIVERSIDADE FEDERAL DE MATO GROSSO, 2019, p. 152).

\section{SEMINÁRIO DE EDUCAÇÃO A DISTÂNCIA}

Diálogos sobre EaD e uso das TDIC na educação: regulamentação em tempos recentes 
Ao examinar o Eixo de Ensino, constatou-se que o elemento nele enfatizado é a autoavaliação de cursos, como aspecto impulsionador da conquista de maior qualidade, bem como de uma possível forma de diminuir a evasão dos discentes, que consiste em outra meta a ser alcançada. Ainda no que se refere a esse eixo, no item 9.1, que traz a previsão de abertura de cursos de graduação presencial e a distância, no que se refere a esta modalidade, observouse que a concretização dessa oferta para o período de 2019 a 2023 reside na dependência da abertura do edital DED/CAPES $\mathrm{n}^{\circ}$ 05/2018, ainda em tramitação (UNIVERSIDADE FEDERAL DE MATO GROSSO, 2019). Outro aspecto em destaque reside no fato de que, semelhante ao Eixo de Gestão, a parceria também é enfatizada como forma de oferta de cursos, através de convênios, contratos e congêneres.

Quanto ao Eixo de Pesquisa e Inovação, as metas apontadas remetem à possibilidade de oferta de cursos stricto sensu por meio de programas de pós-graduação profissionalizantes. Nesse sentido, cabe destacar o Mestrado Profissional em Rede de Tecnologia Educacional, aprovado pela Resolução CONSEPE n ${ }^{\circ} 33$ de 24 de maio de 2018 e homologado pela Resolução CONSEPE $\mathrm{n}^{\circ} 44$ de 9 de julho de 2018, que será desenvolvido valendo-se de parcerias interinstitucionais, que também atende ao que é indicado no Eixo de Gestão. Além desse, com a Resolução CONSEPE No 99 de 29 de julho de 2019, houve a aprovação do Curso de Mestrado Profissional em Tecnologias da Educação (ProfTEC), na modalidade a distância. Esses dois cursos foram elaborados e serão viabilizados sob a responsabilidade de docentes do IE da UFMT.

Já no item 8 desse documento, intitulado "Oferta de Educação a Distância", mais especificamente nos itens 8.3 e 8.4, são apresentadas, respectivamente, a "Infraestrutura física, tecnológica e de pessoal projetada para a sede e para os polos de $\mathrm{EaD}$, em consonância com os cursos a serem ofertados" e a "Descrição das metodologias e das tecnologias adotadas e sua correlação com os projetos pedagógicos dos cursos previstos". No que se refere ao item 8.3, é descrita a infraestrutura física e tecnológica disponível na SETEC e as equipes de profissionais disponíveis para atender os cursos $\mathrm{EaD}$ da instituição. Além disso, esses mesmos aspectos são apontados no que tange aos Polos de Apoio Presenciais. Quanto ao item 8.4, menciona as três 
dimensões desenvolvidas pela SETEC: a Educação a Distância; a Inovação em Tecnologia Educacional para diferentes modalidades educacionais (presencial, aberta e a distância) e a viabilização de programas e projetos interdisciplinares em parceria com a rede pública por meio do uso das novas TIC, dimensões essas que convergem com os Eixos de Ensino, Extensão e Gestão (UNIVERSIDADE FEDERAL DE MATO GROSSO, 2019). Outrossim, enfatiza a convergência entre o presencial e o processo metodológico sustentado pelas novas TIC mormente utilizadas na modalidade a distância e mais recentemente na educação híbrida. Aspecto esse que atende ao parágrafo único do art. $7^{\circ}$ da Portaria Normativa $n^{\circ} 11$ de 20/06/2017 que indica que deve estar previsto no PDI das IES a "cooperação institucional entre a modalidade presencial e a distância" (BRASIL, 2017a).

E no item 12, intitulado "Perfil do corpo docente e de tutores de Educação a Distância", são apresentados os requisitos básicos para desenvolvimento de atividades nessa modalidade na instituição, voltados para o corpo docente; critérios de seleção e contratação de docente e tutores; procedimento para substituição do docente. Esses pontos estão de acordo com aqueles indicados pelas normativas do Programa UAB. Ademais, salienta a Resolução CONSEPE $n^{\circ}$ 158/2010 quanto à possibilidade de registrar as atividades docentes na EaD no Plano Individual de Atividades (PIA) e o regime de trabalho/carga horária do docente e dos tutores (UNIVERSIDADE FEDERAL DE MATO GROSSO, 2019).

Ao analisar os PDI/PPI (2005-2012; 2013-2018; 2019-2023), verificou-se que a EaD consta nos objetivos e nas metas institucionais. O primeiro documento (2005-2012) faz menção à modalidade quando apregoa a continuidade e ampliação de programas de formação docente e de programas de educação a distância. Nesse ponto, vê-se que a importância dada à política de formação de professores em exercício está calcada na parceria interinstitucional, principalmente no trabalho do NEAD/IE, por efeito do número significativo de vagas ofertadas desse curso ao longo de mais de uma década.

Esses aspectos também aparecem e são ratificados nos PDI 2013-2018 e 2019-2023, que aludem com a expectativa de ampliar os cursos de graduação, pós-graduação e capacitação na modalidade a distância. No PDI 2013-2018, é ressaltada a importância do fortalecimento dos 
polos de apoio presencial e a necessidade de estreitar as relações entre a UFMT e seus mantenedores, em face do Sistema UAB. Aspecto este que também é enfatizado no PDI 20192023, mencionado nos Eixos de Ensino e Gestão, ratificando a tradição institucional de estabelecer parcerias com o Estado e prefeituras municipais na viabilização de projetos de formação acadêmica, mormente a formação de professores. Nesses mesmos documentos, também é enfatizada a necessidade de criar e modernizar a infraestrutura de TIC na UFMT, por julgá-la um elemento balizador do desenvolvimento da tecnologia educacional e no suporte aos cursos EaD e, atualmente, à educação híbrida.

Outro pormenor observado é que tanto no PDI/PPI 2013-2018 quanto no PDI/PPPI 2019-2023 é indicada a possibilidade de nos projetos dos cursos de graduação presenciais, conforme o art. $2^{\circ}$ da Portaria $n^{\circ} 1.428$ 28/12/2018, inserir "a oferta de disciplinas na modalidade a distância na organização pedagógica e curricular de seus cursos de graduação presenciais regularmente autorizados, até o limite de $20 \%$ (vinte por cento) da carga horária total do curso" (BRASIL, 2018). Com a revogação dessa normativa pela Portaria MEC n ${ }^{\circ} 2.117$ de 06/12/2019, as IES têm a possibilidade de inserir oferta até o limite de 40\% da carga horária total do curso na carga horária na modalidade de $\mathrm{EaD}$ na organização pedagógica e curricular de seus cursos de graduação presenciais (art. $2^{\circ}$ ) (BRASIL, 2019). Contudo, a não existência de regulamentação interna acerca dessa questão na instituição acaba por refrear as ações da EaD e de legitimar a educação híbrida, indicada no item 8.4 do PDI/PPPI 2019-2023.

Outras constatações ainda merecem ser mencionadas a respeito dos dois documentos em análise: a ênfase dada pela EaD no PDI/PPI 2013-2018 aos aspectos tecnológicos e administrativos, não contemplando de forma direta a dimensão pedagógica (BAGATELLI et al., 2017). Já no PDI/PPPI 2019-2023, a dimensão pedagógica é contemplada principalmente no item 8.4. Nele são apontas as três dimensões $(\mathrm{EaD}$; inovação na tecnologia educacional voltada para a educação presencial, aberta e a distância; programas e projetos interdisciplinares) a serem desenvolvidas pela SETEC. Além disso, são destacados: a hibridação de processos de ensino e aprendizagem possíveis de serem viabilizados em diferentes modalidades; o fortalecimento dos elementos atinentes ao sistema de EaD; e a indicação da necessidade de 


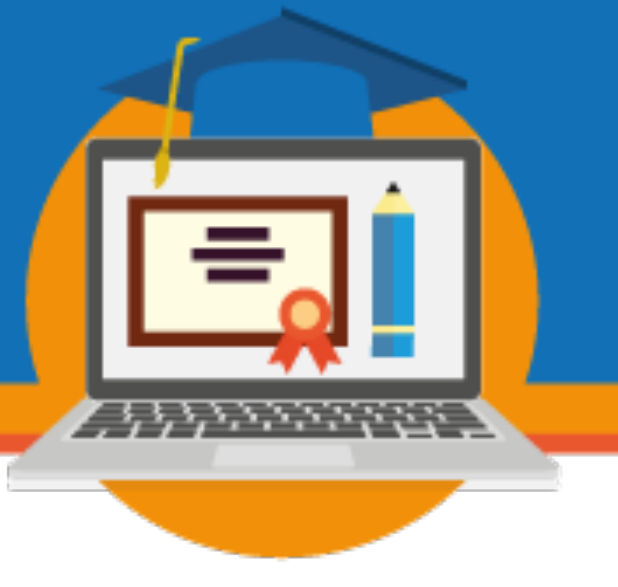

haver autoavaliação dos cursos de graduação $\mathrm{EaD}$, como elemento importante para a consecução de maior qualidade. Outrossim, apresenta como principal estratégia de viabilização dos projetos e programas o estabelecimento de parcerias interinstitucionais.

Contudo, diferentemente do que ocorreu em períodos anteriores da instituição, em que havia a necessidade de formação acadêmica, sobretudo de formação docente, por parte do Estado e das prefeituras municipais, e disponibilidade em investir, o cenário atual de contingenciamentos de verbas públicas parece menos favorável às IPES quando da busca desse tipo de apoio.

Ainda no que se refere especificamente à $\mathrm{EaD}$, nos três documentos analisados observou-se a ausência do conceito institucional de EaD, pautado em uma concepção epistemológica da educação (MATOS, 2016) em que, a partir dela, venham a ser estabelecidos parâmetros internos para EaD. Acredita-se que esse parece ser um dificultador da construção da identidade institucional da modalidade e pode revelar ainda a dependência do Programa UAB, como pode-se constatar no item 12 do PDI/PPPI 2019-2013, em que os quesitos para o desenvolvimento das atividades dessa modalidade continuam a atender a visão e o modelo de $\mathrm{EaD}$ proposto pelo referido programa. Isso se deve ao fato de que os editais da Capes são ainda o único meio de promover a oferta de cursos a distância nas IPES e boa parte das fontes de financiamento advém da UAB.

\section{Considerações finais}

A EaD consiste em uma nova prática educativa e social, que é peculiar na forma de organizar os processos formativos, pautados na mediação pedagógica e mediatização tecnológica (PRETI, 2009). Em vista disso, ao ser introduzida em uma IES, é necessário que essa modalidade esteja presente na sua política e planejamento e seja organizada de modo que sejam oferecidas as condições para sua viabilização. Nesse vértice, buscou-se, no presente trabalho, identificar quais políticas e estratégias foram eleitas para essa modalidade educativa no Plano de Desenvolvimento Institucional (PDI) e no Plano Pedagógico Institucional (PPI) da UFMT.

\section{SEMINÁRIO DE EDUCAÇÃO A DISTÂNCIA}

Diálogos sobre EaD e uso das TDIC na educação: regulamentação em tempos recentes 3 a 6 de novembro de 2020 - Brasília/DF - Online 
A partir do exposto ao longo do trabalho, constatou-se que nos três PDI/PPI da UFMT, a EaD veio sendo inserida nas políticas, nos objetivos, nas metas e nas estratégias da instituição, o que revela que a modalidade obteve importância crescente nas políticas institucionais. No PDI/PPI 2005-2012, a EaD é mencionada devido ao contexto de oferta de curso de graduação voltado para a formação docente que estava inserido em uma política interinstitucional e, sobretudo, devido ao lastro e aos resultados robustos do trabalho desenvolvido pela equipe do NEAD/IE. Em face do contexto em que se encontrava sendo desenvolvido o curso do NEAD/IE, havia a perspectiva de ampliação da oferta, com uma possibilidade de democratização de acesso à graduação.

No PDI/PPI 2013-2018, foi quando a modalidade veio efetivamente a fazer parte de duas políticas estruturantes com objetivos, metas e estratégias claros para a modalidade, com ênfase no desenvolvimento de estrutura administrativa e infraestrutura tecnológica que favorecesse a viabilização e evolução da modalidade no interior da instituição.

Já no PDI/PPPI 2019-2023, a modalidade encontra-se diluída nos objetivos e nas metas dos quatro eixos (Ensino; Pesquisa e Inovação; Extensão; Gestão), mas não são expostas claramente as estratégias de viabilização dos objetivos neles propostos. Por outro lado, os aspectos da oferta de $\mathrm{EaD}$ (infraestrutura física, tecnológica e de pessoal e os processos metodológicos inerentes à modalidade), a previsão de oferta de cursos e o perfil do docente e tutores que atuam na modalidade são apresentados em itens específicos, o que parece conferir relevância da EaD nesse documento institucional. Todavia, boa parte dessas indicações estão calcadas na oferta e no modelo de EaD do Programa UAB.

Esse aspecto reflete a dependência da instituição, a exemplo das demais IPES ofertantes dessa modalidade, pois os editais são o único meio de elas promoverem a oferta de cursos $\mathrm{EaD}$, pois a maioria das fontes de financiamento advêm do Programa UAB. A ausência de dotação orçamentária na matriz das IPES por parte do Ministério da Educação faz com que a EaD não seja uma atividade permanente nelas, o que acaba por restringir sua consolidação institucional (LIMA; SANTOS , 2018). Ao que parece, a dependência de oferta e orçamentária pode ter sido o fator que acabou por restringir as projeções da modalidade nesse documento. 


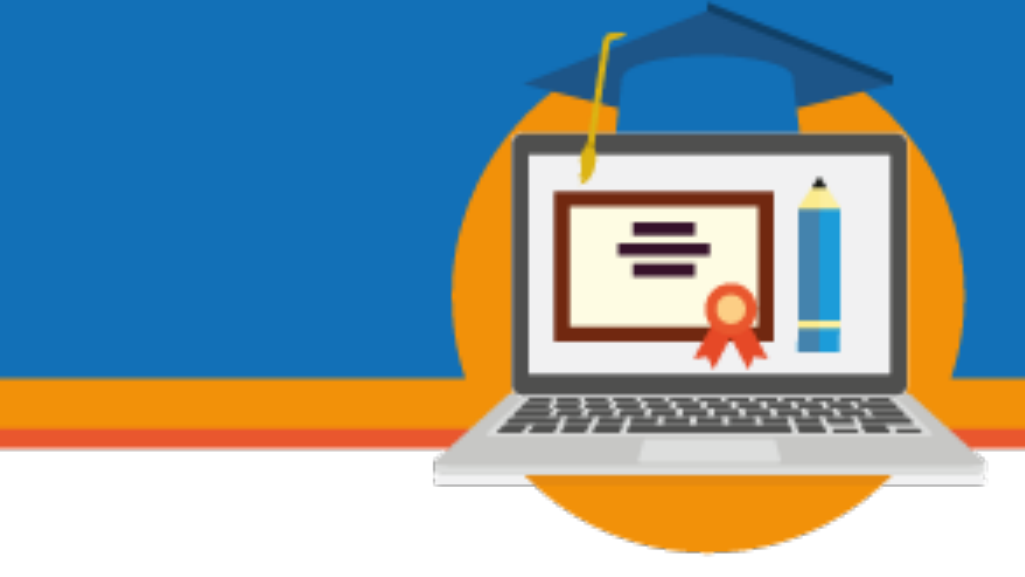

Também foi constatado que em nenhum dos PDI/PPI existe exposto o conceito institucional de $\mathrm{EaD}$, pautado em uma concepção epistemológica de educação, balizadora de parâmetros internos para a modalidade. Aspecto esse que favorece a construção de uma sólida política institucional para a $\mathrm{EaD}$, na qual seja estabelecida os contornos de uma identidade institucional para essa modalidade. Isso implica em elaborar seu projeto próprio de $\mathrm{EaD}$, com objetivos, metas e estratégias de consolidação, como forma de assegurar novas ofertas e a construção de um modelo próprio de $\mathrm{EaD}$ (PETTER et al., 2019). Aspecto esse que parece cada vez mais necessário às IPES, em face da incerteza da continuação do Programa UAB e de um cenário desafiador de contingenciamento orçamentário, que poderão extenuar nelas a oferta de cursos nessa modalidade.

\section{Referências}

ALONSO, Kátia M. Formação de professores em exercício, educação a distância e a consolidação de um projeto de formação: o caso da UFMT. 2005a. 322 p. Tese (Doutorado em Educação) - Unicamp, 2005.

ANJOS, Rosana B. V. dos; ALONSO, Kátia M.; ANJOS, Alexandre M. A implantação de Ambientes Virtuais de Aprendizagem para os cursos presenciais da Universidade Federal de Mato Grosso. In: XI Congresso Brasileiro de Ensino Superior a Distância, 2014, Florianópolis. Anais [...]. Florianópolis, SC: UNIREDE, 2014. p. 397-411.

AZEVEDO, Inês Nava; AZEVEDO, Paola. Políticas para EaD nos Planos de Desenvolvimento Institucional - PDI In: IX Colóquio Internacional sobre Gestão Universitária na América do Sul, 2009, Florianópolis, SC. Disponível em: https://repositorio.ufsc.br/xmlui/bitstream/handle/123456789/36764/Pol\%c3\%adticas\%20para $\% 20$ EAD $\% 20$ nos $\% 20$ planos $\% 20 \mathrm{de} \% 20$ desenvolvimento\%20institucional\%20PDI.pdf?seque nce $=1 \&$ isAllowed $=y$ Acesso em: 5 jan. 2020

BAGATELLI, Elizaine. SAMBRANO, Taciana M.; MACIEL, Cristiano. Interfaces da avaliação institucional da Educação a Distância com o Plano de Desenvolvimento Institucional de uma universidade pública. In: XIV Congresso Brasileiro de Ensino Superior a Distância/ III Congresso Internacional de Educação Superior a Distância, 2017, Rio Grande, RS. Anais ESUD [...]. Rio Grande, RS: UNIREDE, 2017. p. 815-828. 


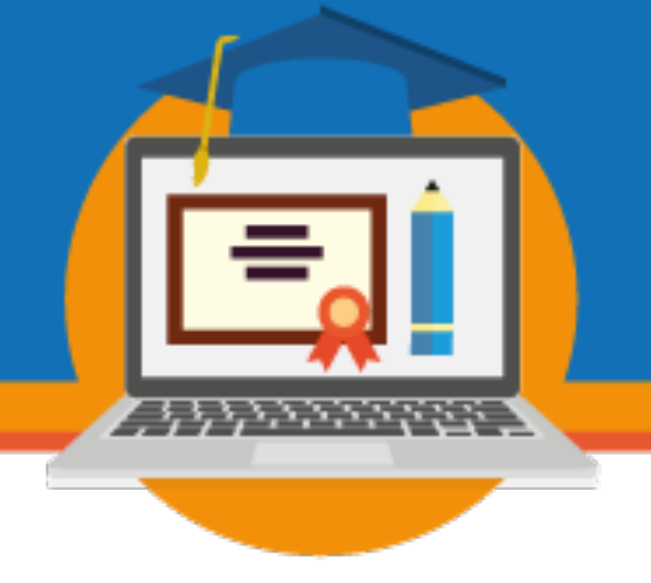

BRASIL. Ministério da Educação. Secretaria de Educação. Plano de desenvolvimento institucional - PDI: diretrizes para elaboração. Brasília, 2004. Disponível em: http://www.eafst.gov.br/pdi/documentos/eixostematicos.pdf. Acesso em: 20 dez. 2019.

BRASIL. Portaria Normativa $\mathbf{n}^{\circ} 11$ de 20 de junho de 2017. Estabelece normas para o credenciamento de instituições e a oferta de cursos superiores a distância, em conformidade com o Decreto no 9.057, de 25 de maio de 2017. Brasília-DF: Presidência da República, 2017a. Disponível em: http://portal.mec.gov.br/docman/maio-2017-pdf/66431-portaria-normativa-11pdf/file. Acesso em: 20 dez. 2019.

BRASIL. Decreto $\mathrm{n}^{\circ} 9.235$ de 15 de dezembro de 2017. Dispõe sobre o exercício das funções de regulação, supervisão e avaliação das instituições de educação superior e dos cursos superiores de graduação e de pós-graduação no sistema federal de ensino. Brasília-DF: Presidência da República, 2017b. Disponível em: https://www.semesp.org.br/wpcontent/uploads/2017/12/DECRETO-N\%C2\%BA-9.235-DE-15-DE-DEZEMBRO-DE2017.pdf. Acesso em: 18 dez. 2019.

BRASIL. Portaria $\mathbf{n}^{0} 1.428$ de 28 de dezembro de 2018. Dispõe sobre a oferta, por Instituições de Educação Superior - IES, de disciplinas na modalidade a distância em cursos de graduação presencial. Brasília-DF: Ministério da Educação, 2018. Disponível em: http://pesquisa.in.gov.br/imprensa/ jsp/visualiza/index.jsp?data=31/12/2018\&jornal=515\&pagina $=59 \&$ totalArquivos $=184$. Acesso em: 19 dez. 2019.

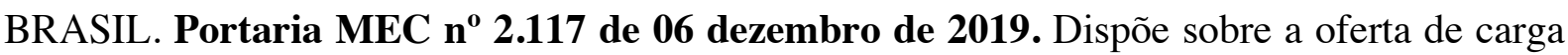
horária na modalidade de Ensino a Distância - EaD em cursos de graduação presenciais ofertados por Instituições de Educação Superior - IES pertencentes ao Sistema Federal de Ensino. Brasília-DF: Ministério da Educação, 2019. Disponível em: https://www .semesp.org.br/wp-content/uploads/2019/12/PORTARIA-MEC-N\%C2\%BA2.117-DE-6-DE-DEZEMBRO-DE-2019.pdf. Acesso em: 19 dez. 2019.

FERREIRA, Marcello; MILL, Daniel. Institucionalização da educação a distância no Ensino Superior público brasileiro: desafios e estratégias. In: REALI, Aline M. M. R.; MILL, Daniel R. S. (org.). Educação a Distância e Tecnologias Digitais: reflexões sobre sujeitos, saberes, contextos e processos. São Carlos: EdUFSCar, 2014. 330p.

FLICK, Uwe. Introdução à pesquisa qualitativa. Porto Alegre: Artmed, 3. ed. 2009.

LIMA, Daniela da Costa B. P.; SANTOS, Catarina de A. Editorial. In: LIMA, Daniela da Costa B. P. (coord.). Relatório Final: A institucionalização da Educação Superior a Distância nas Universidades Federais da Região Centro-Oeste: processos, organização e práticas. Goiânia: UFG, v. 1, n.6, 2018. 


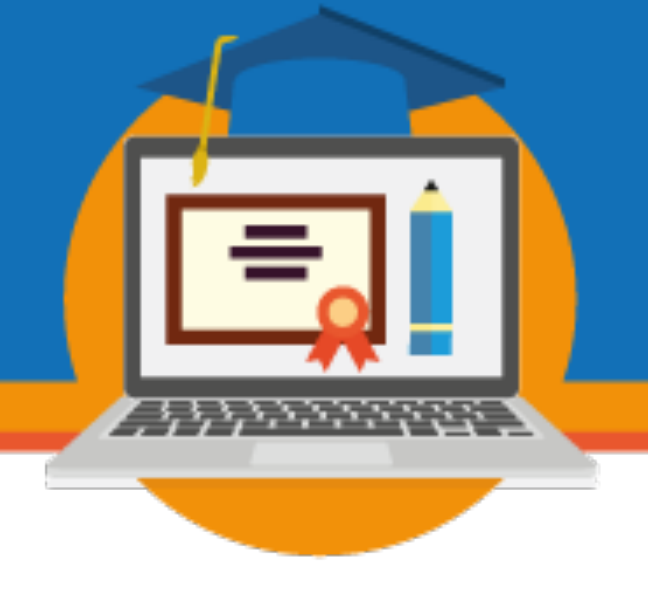

LÜDKE, Menga; ANDRÉ, Marli E. D. A. Pesquisa em Educação: abordagens qualitativas. São Paulo: EPU, 1986.

MATOS, Heloneide A. Educação a Distância: um estudo das instituições públicas de educação superior no Estado de Mato Grosso. 2016. 183p. Dissertação (Mestrado em Educação) - Instituto de Educação, Universidade Federal de Mato Grosso, Cuiabá, 2016.

PETTER, Rosemery C.; Percurso e processo de institucionalização da Educação a Distância da Universidade Federal de Mato Grosso. 2019. 338f. Tese (Doutorado em Educação) - Instituto de Educação, Universidade Federal de Mato Grosso (UFMT), 2019.

PETTER, Rosemery C. SAMBRANO, Taciana M.; MACIEL, Cristiano. Educação a Distância em Instituições Públicas de Ensino Superior: algumas considerações sobre o processo de institucionalização. In: XVI Congresso Brasileiro de Ensino Superior a Distância/V Congresso Internacional de Educação Superior a Distância, 2019, Teresina, PI. Anais ESUD [...]. Teresina, PI: UNIREDE, 2019. p. 134-144.

PRETI, Oreste. Educação a Distância: fundamentos e práticas. Cuiabá: EdUFMT, 2009. $174 \mathrm{p}$.

PRETI, Oreste; ALONSO, Kátia M. O Núcleo de Educação Aberta e a Distância da UFMT: uma mirada para um passado presente (1992-2005). Revista de Educação Pública, Cuiabá: EdUFMT, v. 25, n.59, p. 312-327, maio/ago. 2016.

UNIVERSIDADE FEDERAL DE MATO GROSSO. Pró-Reitoria de Planejamento. Plano de Desenvolvimento Institucional (2005-2012). Cuiabá: UFMT, 2007. Disponível em: http://www.ufmt.br/proplan/arquivos/ed3eb6dc85f79319d436cb7c2fa05d7c.pdf. Acesso em: 22 dez. 2019.

UNIVERSIDADE FEDERAL DE MATO GROSSO. Plano de Desenvolvimento Institucional (2013-2018). Cuiabá: UFMT, 2013, 110p. Disponível em: http://www.ufmt.br/proplan/arquivos/4df326c111023870f9d4db6c49077e98.pdf. Acesso em: 21 dez. 2019.

UNIVERSIDADE FEDERAL DE MATO GROSSO. Plano de Desenvolvimento Institucional (2019-2023). Cuiabá: UFMT, 2019, 203p. Disponível em: https://www1.ufmt.br/pdiufmt/arquivos/a4e4a963aab7dc8d8cc561b45a1eb965.pdf. Acesso em: 21 dez. 2019. 


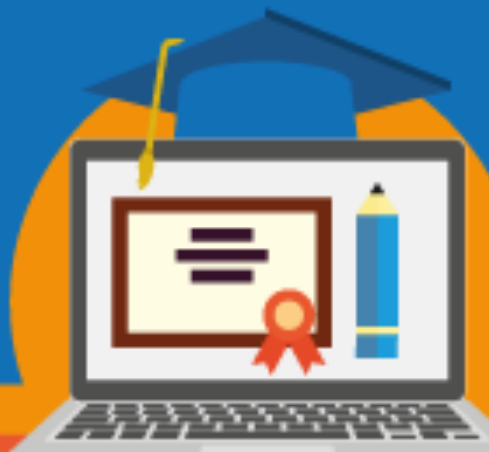

III SEMINÁRIO DE EDUCAÇÃO A DISTÂNCIA

Diálogos sobre EaD e uso das TDIC na educação: regulamentação em tempos recentes 3 a 6 de novembro de 2020 - Brasília/DF - Online 